\title{
Dialectics of Nominal and Real Power in the Ukrainian and World Politics
}

\author{
Denys Svyrydenko
}

Doctor of Philosophy, Associated Professor, National Pedagogical Dragomanov University

(Kyiv, Ukraine)

E-mail: denis_sviridenko@ukr.net

ORCID: 0000-0001-6126-1747

\section{Olena Yatsenko}

PhD, Associated Professor, National Pedagogical Dragomanov University (Kyiv, Ukraine)

E-mail: yatsenkood@gmail.com

ORCID: 0000-0003-0584-933X

The philosophical problem of representation becomes of particular relevance in modern politics. Publicity and responsibility of the power for the effectiveness of its work creates a differentiation to the nominal and real power. There is a dual tendency: the subjects of real power delegate proxy to the representatives of the nominal power, trying to avoid publicity and responsibility. Representatives of the nominee power create an impression of the reality and effectiveness of the realization of power. The dialectic of nominal and real power in society is carried out by means of the formation of surrogate forms of government: democracy-monarchy, democracy-oligarchy, democracy-aristocracy; ductility in the work of state institutions and commercialized support by the creative class. To direct the contradictions of nominal and real power in a productive direction is possible by increasing the publicity and responsibility of the subjects of power.

Key Words: nominal power, real power, noumenal power, creative class, social freedom, democratic liberalism

Received January 15, 2018; accepted April 12, 2018

Ukrainian Policymaker, Volume 2, 2018: 33-40

DOI: $10.29202 /$ up/2/5

\section{Introduction}

Modern information society produces an increasing role of representative processes and phenomena. Widespread use in the humanities embodies the concept of simulation, or simulative

(C) Svyrydenko, Denys, 2018

(C) Yatsenko, Olena, 2018 
reality. According to the philosophy of postmodernism, which accurately describes the state of socioculture precisely, modernity operates symbols of such order, which for its effective application do not require substantiation in reality. Hens, the representation are legitimized as a self-sufficient process that offends ontological essence. The fundamental metaphysical problem of essence and phenomenon has lost the preconditions of its relevance. This is a very comfortable position for the time of conformism. This convenience lies at the heart of manipulative practices that are widely used in all areas of modern life: from economics to art, from everyday practice to high politics. Simulative reality produces a gap in the ontological reality in many respects, and in politics too. This gap of reality and simulation in the political realm produces dialectic of nominal and real power.

Along with the simulation, modern conformism is characterized by an increasing role of communication. Indeed, modern communications technology greatly enhances the potential for impact on the general public. At the same time, communication technologies substantially change the boundaries of public and private. Therefore, the subjects of real power in society often seek to avoid excessive attention from the community. Increasing the scale of the information space, in turn, leads to the differentiation of real and nominal. The freedom of speech is also an important criterion for the life of a democratic society. Communication is both a way and a method of ensuring it. But freedom of speech has the purpose of transparency of the actions of the authorities and its relevant reporting to society. It is clear that the declared liberalism of the modern era exacerbates the eternal struggle of interests of both the subjects of power and the general public. In the conditions of information and communication freedom, the authorities, with the rest, are forced to play hide-and-seek with their own voters. This article is devoted to the study of the dialectics of real and nominal power in contemporary Ukrainian politics.

\section{Theoretical and Methodological Basis of the Study}

The phenomenon of power has a long history of research and analysis. Modern society produces new challenges and requests for feminization and mechanisms for the realization of power. As the organization of society is being pursued, there are also new forms of exercise of power, including political ones. The hierarchy of power relations, accumulated in social welfare through the power of the genus, the power of the nation, the power of the state, the power of civilization in the modern space of socioculture does not disappear and does not lose its relevance. However, the logic of the realization of power relations in modern society forms and covers qualitatively new problems and perspectives of the discourse of power.

There is a widespread differentiation of the phenomenon of power in modern research literature, considering the mechanism of its implementation. Thus, primary power is interpreted as physical coercion, implemented through a policy principle, or investment of one's own freedom and will in a supersonic integrity, community or state as a result of hopelessness. The personification of this invested capital of freedom and the will of the general public is a specific subject of power: the monarch, the feudal lord, or the leader. Such subordination is due to the power relations, therefore, the reality of the government is supported by its application, and the level of social tension is steadily high.

The next algorithm for the implementation of power relations is based on a functional or teleological principle. T. Parsons, one of the most prominent of his ideologues, convinced that power is the mobilization of resources for the purpose. This type of power subordination is 
based no longer on the force of physical coercion, but on the basis of economic feasibility and effectiveness. Freedom is invested not in the person of the subject of power, but in a certain ideological basis, the idea of the values that determine and guide the course of life. Thus, there is a gradual discreteness of the phenomenon of power in society, and on the other the formation and growth of an ontological gap between nominal and real power is taking place. Investments of freedom are no longer characterized by irreversibility, forced alienation. Therefore, the range of social discontent forms the leverage of influence on power. Accordingly, carriers of real power in society begin to delegate representative functions to other subjects of power, who have the opportunity to be responsible for certain defects in the work.

The modern day of the information society significantly complicates the hierarchy and structure of power relations. Therefore, the implicit topic of power research is inferior to the essentially. The discreteness of power is extrapolated into the "collective phenomenon of social consensus" (H. Arendt), the "spraying of power relations" (M. Foucault), the postmodern discourse of anonymous and irrational power, the totalitarian nature of power from the primitive society to modern democratic liberalism (A. Glucksmann), the real and the symbolic capital of power (P. Bourdieu). Consequently, at the present stage, the contradiction between real and nominal power is exacerbated.

The modern Ukrainian politician is going through terrifying transformations. Post-colonial development tendencies pose serious challenges to civil society and its management system. Therefore, Raisa Naumenko notes the following: "Thus, a real revolution is taking place in a global world, both in content, in methods, and in the forms of government. The destiny of the destroyer-revolutionaries who seek to change the modern Ukrainian state is sad. After all, they will have to start building a new one after they destroy the old one. However, they are not ready for such work" [Naumenko, 2018: 110]. Such a disposition is due, among other things, to the unstable post-colonial motivation of the power. Oleg Bazaluk and Denys Svyrydenko explain this imbalance by the metaphor of rhizomes: "The problem lies in the rhizome in the plane of understanding of the difference between space-aggressors and space-victims, which include all the limitrophe states" [Bazaluk \& Svyrydenko, 2018: 94]. The dialectic of will and coercion in the interpretation of the phenomenon of power often creates grounds for emotional assessments of political activity and the growth of social tension. Colin Hay and Gerry Stoker are explicit it so: "Contemporary political disaffection is not, we suggest, a story of the decline of civic virtue, nor is it a story of political apathy - it is one of disenchantment, even hatred, of politics and politicians" [Hay \& Stoker, 2009: 226]. In addition, the question arises whether nominal power is capable of performing real functions? These authors say: "We think the government and political elites more generally (and not just in the UK) have failed fully to recognise the scale, depth and nature of the democratic political malaise we face" [Hay \& Stoker, 2009: 227]. One of the daemons of modern democracy, or the most common form of abuse of power, is corruption. We are convinced that corruption should be considered as a consequence of the collision of nominal and real power. After all, "Democratization, where it has survived with any substance, has often been accompanied by spreading corruption, a decline in public order and an erosion of the administrative capacity and authority of the state" [White, 1998: 3]. The multi-vector of political activity to some extent disorients the subjects of power, necessarily reduces the effectiveness of their activities, and forms signs of political instability in public life. Such a situation makes it possible to verify certain tendencies in the discourse of power. Simon Susen thus defines the various trends in the exercise of power: "This tendency appears to suggest that it is possible to distinguish fundamental types of power in 
binary terms. In this respect, the following conceptual oppositions are especially important: (1) 'soft power' vs. 'hard power', (2) 'power to' vs. 'power over', and (3) 'power for' vs. 'power against'" [Susen, 2017: 22]. In addition to the above-mentioned multidirectional discourse of power in society there are upward trends in self-organization of citizens for the achievement of a common goal. So must a civil society, which is the goal of democratic liberalism. Therefore, it is fair to note Tiina Rättilä and Jarmo Rinne: "Like many other forms of new social movements and civic activism, resident activism operates outside formal political institutions and is motivated by the prospect of engaging in do-it-yourself (DIY) politics at the grassroots level" [Rättilä \& Rinne, 2017: 1].

\section{Mechanisms of Nominal and Real Power}

The complication of the social structure in the course of historical development predetermines the extrapolation of the discourse of power to the extremely broad context of sociocultural. The social will of the era of primitive society and modern processes of globalization require different mechanisms for the implementation and legitimization of power. In place of physical coercion and economic dependence, manipulative practices are widely implemented. It is clear that manipulative practices are implemented against the background of a symbolic or semiotic space. Therefore, real power is forced to operate successfully with nominal meanings, reinforcing the impression of its own competence. The criterion of such competence in the eyes of society is the effectiveness and efficiency of the work of the power. That is why the leading politicians of our state seek to associate their name with persons and events that are positively perceived in general, but have nothing to do with the work of the political community. Numerous PR campaigns with outstanding athletes, prize-winners of the Olympiad and Paralympics, subject to the total lack of state support to physical education and sports institutions. Any achievement of our neighbors abroad, or recognition at the international level, is represented by the first persons of the state as a logical achievement of their laborious work. Consequently, success as a criterion for the work of power in the space of symbolic exchange greatly optimizes the dialectic of the nominal and real in the discourse of power. The representation of power as a nominal phenomenon in the era of the information society plays a significant role in the work of both the domestic and world politics. Therefore, the charisma of the leader becomes unimportant in contemporary politics, and leaders of the first countries of the world are becoming young and attractive figures like Justin Trudeau or Emanuel Macron.

The plasticity, networking and the location of the global context of politics in the dialectics of real and nominal power actualize the problem of predictive functions in the course of world history. A striking confirmation of this thesis is the conflict in the east of our country. Unrecognized republics, like their representative leaders, although taking part in the negotiation process on conflict resolution, do not actually have the authority to make and implement decisions. And the country-aggressor by all possible means tries to avoid nominating it as a party, or parties to the conflict. A reviewing the chronicle of the war in Syria, in which more than 70 thousand people have already died, comes the understanding that Ukraine saves exclusively geo-racial closeness to the countries-leaders of world politics and real participants of the conflict. In addition, the UN's work at the present stage, which is not effective in resolving military conflicts, but simply helpless in solving the contradictions and challenges of the modern world, is indicative in the dialectic of real and nominal power.

Nominal and real power is differ from the point of view of representation and institutionality. 
Nominating power acts as representing the interests of the community. That is why the charisma of the leader and the success, efficiency in the work of the nominal power is so important. However, real power is often not concentrated in the hands of official bodies of power, but belongs to certain institutions of statehood, such as the education system, or law enforcement agencies. Is it possible to carry out an illegal referendum on the territory's membership of a particular state, with the absence of support from the educational institutions where this event was held, or under the condition of a good work of the law-enforcement system in this area? It is hardly possible. Except this, there are numerous examples of illegal possession of someone's property during the political instability in Luhansk and Donetsk region during 2014-2018. The conclusion is obvious that institutions of statehood have a significant influence of real power in society. A nominal, representative political power is the governing, but derivative of the basic, fundamental level of the real power of state institutions.

Robert A. Dahl proposes a distinction between the discourse of power on the basis of "connection" (nominal, organizational, representative power) and "causa" (real, determinant, controlling form of government). Indeed, the declarative principles of political economy often do not correspond to the processes that are taking place in reality. Thus, democracy is the most widespread form of social organization in the modern world. However, given the specific conditions for the formation of statehood, the declarative principles of democracy are undergoing significant transformations, resulting in different forms of quasi-democracy. Ukraine, the Russian Federation, and the United States of America - all these countries are democratic in the state system. However, do we have any reason to assert the identity or, at least, the similarity of these democracies? It is obvious that the practical mechanisms of the exercise of state power in these countries are significantly different. Declaratively proclaimed democracy in the Russian Federation in the last two decades demonstrates signs of a monarchical system. Therefore, in the Russian Federation, we observe a quasi-form of democracy-monarchy. Such tendencies can be traced, in particular, in the management technologies of other states of the former Soviet Union: Belarus, Armenia, Azerbaijan, Tajikistan and others. Or the militarized monarchist republic of North Korea clearly manifests the viability of such a quasi-form of government. An interesting nominative tendency of representing power in a totalitarian system is a demonstration of its perfection. Igor Samoylov explains it this way: "A totalitarian state has the intention to demonstrate its own perfection, and there are grounds for that. What can be more perfect than a logical and reasonable system where the government controls all aspects of the life of each individual, from birth, forms his personality, creating a "new man" for which the universal good of the state is the highest goal of existence, constructed in accordance with the ideal concept that arose in the minds of the authors of this social system and became a reality, totalitarianism is a sort of explication of the beginning of the scope of the ideal to the material world" [Samoylov, 2014: 177].

If we analyze the specifics of state power in Ukraine, then the existence of a democracyoligarchy in our country is quite obvious. Nominee political power is delegated not by the people, by the general public, but by separate oligarchic structures. So, Oleg Bazaluk says: "The coming to power of Poroshenko and his inner circle did not change the membership of the Ukrainian ruling "elite" [Bazaluk \& Svyrydenko, 2017: 221]. The basis of motivation in such a policy is the protection of business interests, not social justice and the stabilization of public life. Of course, Ukraine is not unique in its oligarchic democracy. The vast majority of South American countries have been fruitfully implementing similar principles of public administration. 
Moreover, the developed forms of democracy of the advanced countries of the world, such as the USA, France, Germany, can hardly be called democracies in its pure form. Rather, it is certain forms of democracy-aristocracy, when real power is concentrated in the hands of political groups that have tradition, authority and weight of influence on public opinion and the course of social life. Thus, the gap between nominal and real power takes place in countries with different levels of development of democracy: "The change of the political leader and even the political regime in the state does not necessarily exert a significant influence on the will-power-will phenomenon." Despite the changed conditions, the established structure of the power-will relations continues. The power elite of the society in every concrete case prove the conduit of this common will. The change of the imperious phenomenon always leads to a radical restructuring of the life of society, since the former social relations and connections are completely reconstructed" [Samoylov, 2014: 156]. Investigating the principles of legitimizing the oligarchic system of post-colonial states, Igor Samoilov comes to the following conclusions: "Since the oligarchy can exist only in the context of the recognition of the right of private property by the society, the will of the masses to possess even a small part of such property inevitably causes a social need to establish institutions that provide and protect this right, in particular, the state. And, at the same time, the "state of owners", in which each individual is accorded principally equal rights to own property on various scales. It is beneficial primarily to the oligarchic ruling elite, because it receives the greatest benefit from such a social organization" [Samoylov, 2014: 174].

The real subjects of power and nominal representatives of power relations are presented individually in person. Steven Lukes justifies the contradiction between the "unchanging amount of power" in society, emphasizing the totality of the discourse of power; and the power of "short-term", or domination of representative, nominal power. Events in the eastern part of Ukraine are also indicative in this regard. When in 2014 there was a threat to Ukrainian statehood in certain regions of Lugansk and Donetsk region, and then the governors in this area were appointed people who actually kept the full power in these regions: Igor Kolomoisky in the Dnipropetrovsk region, Sergey Taruta, person, close to Rinat Akhmetov in Donetsk. Such appointments were a clear signal that these figures were determined by a civic position and are ready to invest their own time, resources and personal responsibility for asserting Ukrainian statehood. These significant actions by the authorities caused the desired and expected impact on the situation at that time. After all, like the thermal motion of molecules, when some molecules collide with others, people are under the influence of their closest social environment [Samoylov, 2014: 141].

Consequently, the dynamics of power relations in society is carried out through the proletariat of real and nominal power. Such a disposition is conditioned by the internal mechanism of power, namely the tendency to act "Contrary to real interests and preventing possible discontent" [Lukes, 2018: 39]. Nominal power in society performs functions of scenery, or simulation space, under the cover of which the subjects of real power are able to carry out of power.

There is a reverse trend of influence. It is clear that real power needs nominal representation. However, nominal power, in turn, needs support from the real actors of power. In addition, this is not just about the election posts of political power. Igor Samoilov describes the functions of the creative stratum of society on the legitimization of subjects of real power: "Demonstrative, deliberate consumption, which is presented to the society as an "ideal" and the only true direction of will demonstrated by so-called "stars", is manifested, among other 
things, in the phenomenon of glamour. In turn, the creative class, being close to the real power, receives significant material preferences from it. The bright glare of glamour overshadows the real power, which, while remaining in the shadows, actually possesses both power and wealth" [Samoylov, 2014: 173]. And although creativity and art are the realms of spiritual production that accumulate true values. Yes, Galina Shevchenko stresses: "Culture and arts are the catalysts for appearance of excellent humans who have good souls, thoughts and deeds, who feel an urgent necessity to live in accordance with their conscience, to give people joy and happiness" [Shevchenko, 2017: 177]. However, in the age of conformism of art, as well as other cultural projects, it was not possible to avoid commercialization.

\section{Conclusions}

Simulation, or simulation of reality, causes a series of ontological ruptures. The conventional perception of things and phenomena does not guarantee the trustworthiness of knowledge. Extensive and virtuous manipulative practices are widely used in all spheres of modern life, and especially in politics. Therefore, analytics of the contradiction between nominal and real power in the modern information society becomes of special significance. Consequently, nominal power is a representative, public, electoral component of the modern political system. The real power is the political elites, or oligarchic clans, or individual personalities that usurp power beyond the legal field of the state. The distance between the nominal and the real power is determined by the publicity of democratic power, and hence its responsibility. Subjects of real power for obvious reasons seek to avoid both publicity and responsibility. This strategy allows them to hold power for a long time. The ways of legitimizing real power through the nominal are the following: the formation of quasi-forms of a democratic system, the institutionalization of statehood and the so-called "creative class". Nominal democracy of some countries shows signs of opposing state structures: democracy-monarchy in Russia, democracy-oligarchy in Ukraine, aristocracy-democracy in the USA. The institutions of statehood are an intermediate link between nominal and real power. Thus, sabotage by the leaders of local power institutions makes it impossible to coordinate the work of centralized authorities. That is, the institutions of the state have the opportunity, in turn, to enter into object-object relations of manipulation by the authorities. The creative class also plays a significant role in the dialectic of nominal and real power, by popularizing those benefits that accompany real power.

Thus, the differentiation of power into nominal and real in the information society is a natural and inevitable phenomenon. Minimizing the risks of such differentiation is possible by increasing publicity and accountability of government actions.

\section{[D] References}

Bazaluk, Oleg, and Denys Svyrydenko. Philosophy of war and peace: in search of new European security strategy. Anthropological Measurements of Philosophical Research, No. 12, 2017: 89-99.

Hay, Colin, Gerry Stoker. Revitalising politics: have we lost the plot?, Representation, Vol. 45, Issue 3, 2009: 225-236, DOI: 10.1080/00344890903129681

Lukes, Steven. Noumenal power: concept and explanation. Journal of Political Power, Vol. 11, 2018: 46-55. DOI: 10.1080/2158379X.2018.1433755

McGrath, Charles. Master Narratives of Ukrainian Political Culture. Future Human Image, Vol. 9, 2018: 74-81. 
Naumenko, Raisa. Philosophy of Public Governance: Manpower Policy of Modern Ukraine in the Context of Globalization. Philosophy and Cosmology, Vol. 20, 2018: 106-112, DOI: $10.29202 /$ phil-cosm/20/9

Rättilä, Tiina, and Jarmo Rinne. Local Resident Activism and Unofficial Political Representation: New Theoretical Contours. Representation, Vol. 53, Issue 3-4, 2017: 219-231, DOI: 10.1080/00344893.2017.1393454

Samoylov, Igor. Phenomenology of the will in the society of consumption. European Social Science Journal, Vol. 9, No. 1, 2014: 25-27.

Shevchenko, Galyna. The Ideal Image of a Man: the Main Characteristics and Ways of Achieving. Future Human Image, Vol. 7, 2017: 120-127.

Susen, Simon. The seductive force of 'noumenal power': a new path (or impasse) for critical theory? Journal of Political Power. Vol. 11, 2018: 4-45, DOI: 10.1080/2158379X.2017.1362734

White, Gordon. Building a democratic developmental state: Social democracy in the developing world. Democratization, Vol. 5, Issue 3, 1998: 1-32, DOI: 10.1080/13510349808403571 